American Journal of Applied Sciences 5 (7): 783-787, 2008

ISSN 1546-9239

(C) 2008 Science Publications

\title{
Design and Development of Decision Making System Using Fuzzy Analytic Hierarchy Process
}

\author{
Chin Wen Cheong, Lee Hua Jie, Mak Chee Meng and Amy Lim Hui Lan \\ Faculty of Information Technology, Multimedia University, \\ 63100 Cyberjaya, Selangor, Malaysia
}

\begin{abstract}
This article aims to develop a fuzzy Multicriteria Decision Making (MCDM) tool that equips with Analytic Hierarchy Process (AHP) framework to help users in semi-structured and unstructured decision making tasks. The tool provides portability and adaptability features by deploying the software on web platform. In addition, this system provides an integrated domain reference channel via a database connection to assist the user obtains relevant information regarding the problem domain before constructing the AHP hierarchy attributes. Our decision making tool combines the characteristics of real time information retrieval through Internet and MCDM problem analytical processing logic.
\end{abstract}

Key words: Multicriteria decision making, analytic hierarchy process (AHP), fuzzy set theory

\section{INTRODUCTION}

Decision making analysis aims to realize conflicts that occur due to various different opinions, fluctuating environment conditions, subjective assessments, etc. In real world, decision often been made under various alternatives with their associated criteria. Improper final selection may cause unpleasant outcome with undesired results of misuse in resources, manpower as well as precious time. Hence, it is important to achieve an optimal decision in real world problems which involve multiple alternatives and criteria in qualitative and quantitative domains.

One of the famous Multicriteria Decision Making (MCDM) methodology is the Analytical Hierarchy Process (AHP) pioneers by Saaty ${ }^{[1,2]}$. Voluminous literatures have applied the framework of AHP for modeling unstructured problems in the areas of economics $^{[3,4]}$, social ${ }^{[5]}$, industrial ${ }^{[6,7]}$ and military ${ }^{[8,9]}$. Due to its effectiveness and popularity, commercial software such as Expert Choice (http://www. expertchoice.com), Web-HIPRE (http://www.hipre. hut.fi), Criterium DecisionPlus (http://www. infoharvest.com) and ERGO (http://www. technologyevaluation.com) are adopting their systems and designs base on the AHP framework.

One of the important procedures in AHP is the pair-by-pair comparison values for a set of predefined objects (alternatives). The AHP requires the decision makers furnish with complete information and ample knowledge of all aspects of the problem statements during their judgments under a predefined semantic scale. However, the nature of the real-world problems often relates to fuzziness and ambiguousness which initiates by the unprecedented environment conditions, human factors, incomplete information and etc. Numerous studies ${ }^{[10-12]}$ implement the fuzzy set theory in the AHP problem to tolerate the vagueness conditions.

In this study, we develop an AHP multicriteria decision making tool which equips with fuzzy set theory ${ }^{[13]}$ to tolerate the fuzziness in decision maker's judgements. Most of the current AHP decision support commercial software is largely bases on the local machine executable format where user needs to setup the software prior to use. In our system design, we provide portability and adaptability features by deploying the software on web platform. In addition, this tool provides an integrated domain reference channel via a database connection to assist the end user obtain relevant information regarding the problem domain before constructing the AHP hierarchy tree. Hence, our decision making tool combines the characteristic of real time information retrieval through internet and MCDM problem analytical processing logic.

\section{MATERIALS AND METHODS}

System development: We select Visual Studio.NET (http://msdn2.microsoft.com) as our compiler in the

Corresponding Author: Chin Wen Cheong, Faculty of Information Technology, Multimedia University, 63100 Cyberjaya, Selangor, Malaysia 
software development phase. NET platform offers a new software development model that allows applications create in disparate programming languages to communicate with each other. In addition, NET architecture also offers Web services which allow applications in the Internet. C\#.NET is our main language in the coding phase. We adopt C\#.NET application into web application using ASP.NET (http://www.asp.net). We find it useful with various

State diagram of decision making tool (Part 1 of 2)

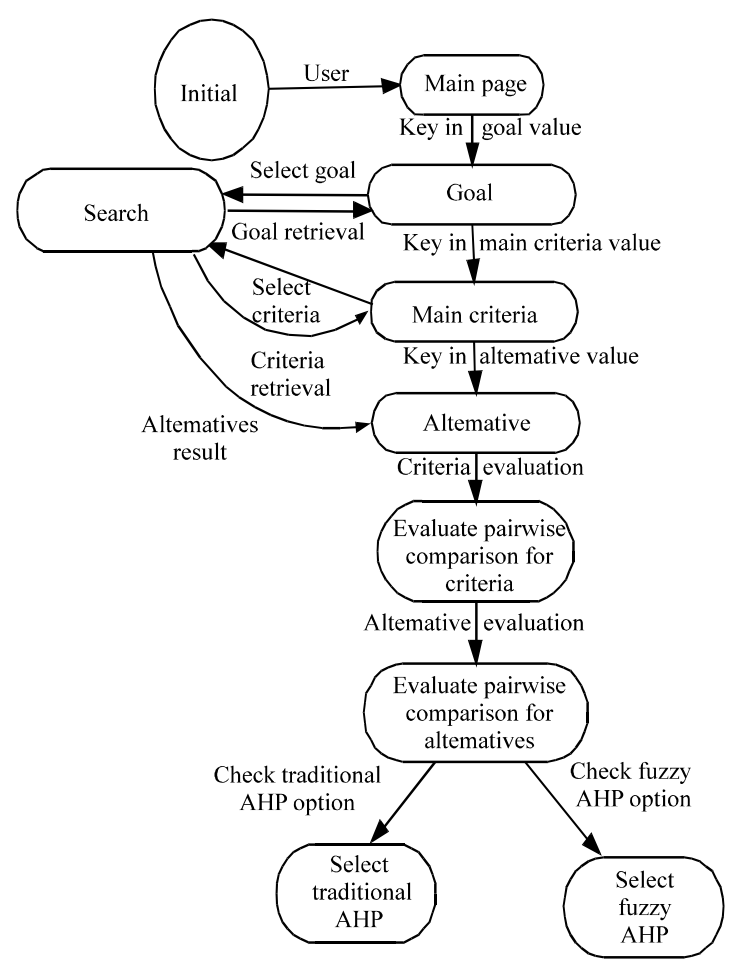

functions of ASP.NET to be deployed into our tool. Among the applications of ASP.NET are session variables concepts for passing data in different pages, usage of data grid and panels which are useful for structuring the output, WYSIWYG (what you see is what you get) features and also support various other third party component. The system architecture design, state transition diagram and use case diagram are illustrated as follows:

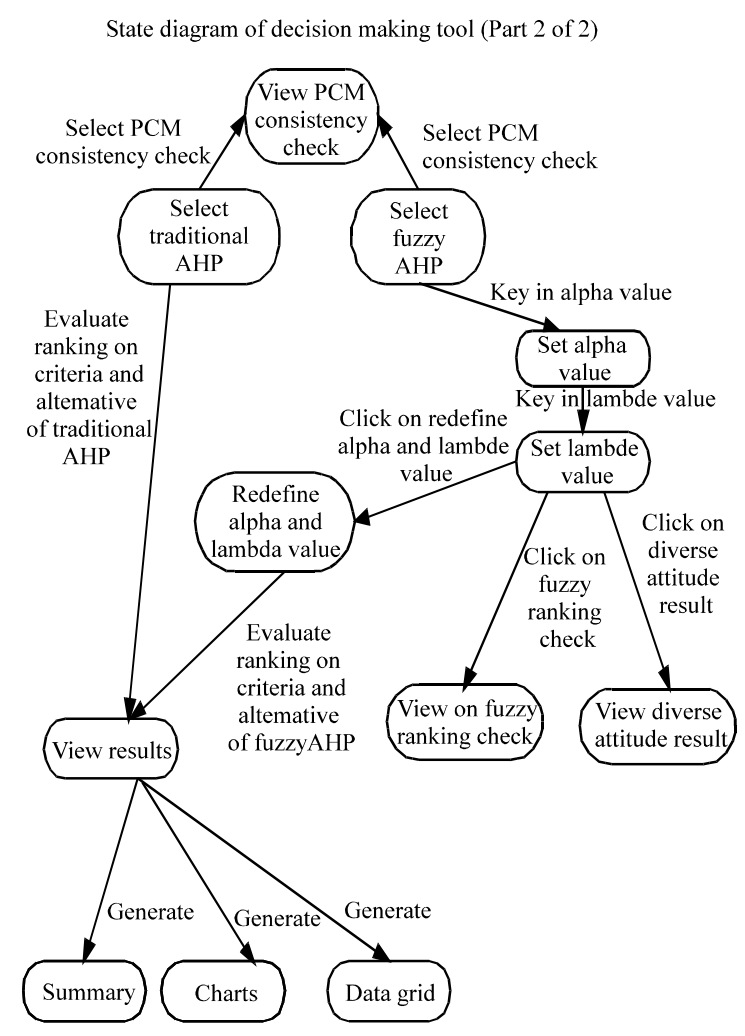

Diagram 1: State transition diagram

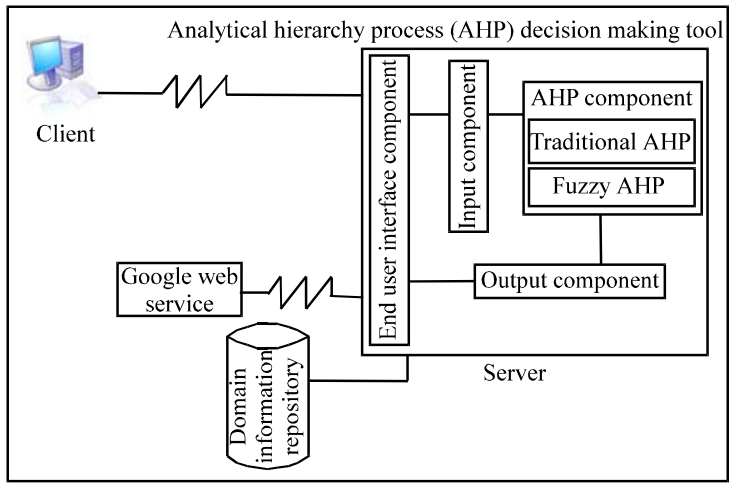

Diagram 2: Architecture Design 
Am. J. Applied Sci., 5 (7): 783-787, 2008

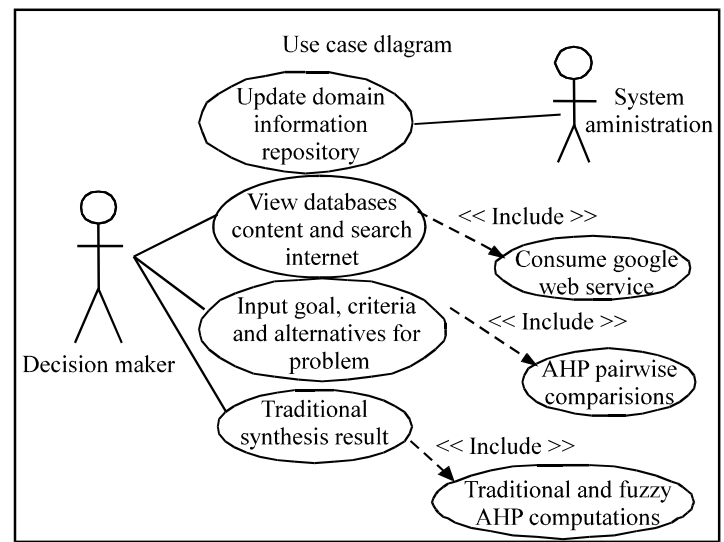

Diagram 3: Use case Diagram

\section{Computational algorithms}

Step1: Fuzzy pairwise comparison matrices: Due to simplicity and effectiveness, we select triangular fuzzy number as a reference to indicate the influence strength of each element in the hierarchy structure. Given a evaluation scale (Table 1) indicates from scores 1/9 to 9 , the scores are fuzzified by the triangular fuzzy number $\mathrm{f}=(1, \mathrm{~m}, \mathrm{u})$ where 1 and $\mathrm{u}$ are the lower and upper bounds that represent the vagueness in the preferences scores.

The fuzzy pairwise comparison matrix, $\tilde{\mathrm{P}}$, is defines as:

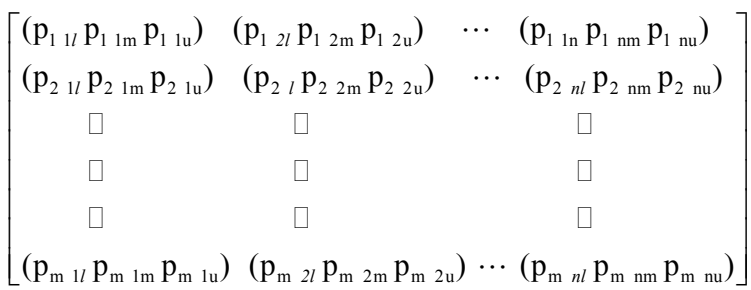

Step 2- Fuzzy weighted performance matrix: We define the weight measurement of each criterion and the performance of respected alternative performance as follows:

$$
\tilde{\omega}_{\mathrm{j}}=\left[\begin{array}{llll}
\left(\mathrm{w}_{11} \mathrm{w}_{1 \mathrm{~m}} \mathrm{w}_{1 \mathrm{u}}\right) & \left(\mathrm{w}_{21} \mathrm{w}_{2 \mathrm{~m}} \mathrm{w}_{2 \mathrm{u}}\right) & \ldots & \left(\mathrm{w}_{\mathrm{nl}} \mathrm{w}_{\mathrm{nm}} \mathrm{w}_{\mathrm{nu}}\right)
\end{array}\right]
$$

$$
\tilde{\mathrm{A}}_{\mathrm{i}}=\left(\begin{array}{c}
\left(\mathrm{a}_{111} \mathrm{a}_{11 \mathrm{~m}} \mathrm{a}_{11 \mathrm{u}}\right) \\
\left(\mathrm{a}_{211} \mathrm{a}_{21 \mathrm{~m}} \mathrm{a}_{21 \mathrm{u}}\right) \\
\cdot \\
\cdot \\
\cdot \\
\left(\mathrm{a}_{\mathrm{ijj}} \mathrm{a}_{\mathrm{ijm}} \mathrm{a}_{\mathrm{iju}}\right)
\end{array}\right) ;
$$

Table 1: Evaluation scales

\begin{tabular}{llll}
\hline Score & fuzzy No. & Score & fuzzy No. \\
\hline 1 & $(1,1,1)$ if diagonal; & $1 / 1$ & $(1,1,1)$ if diagonal; \\
& $(1,1,3)$ otherwise & & $(1,1,3)$ otherwise \\
2 & $(1,2,4)$ & $1 / 2$ & $(1 / 4,1 / 2,1 / 1)$ \\
3 & $(1,3,5)$ & $1 / 3$ & $(1 / 5,1 / 3,1 / 1)$ \\
4 & $(2,4,6)$ & $1 / 4$ & $(1 / 6,1 / 4,1 / 2)$ \\
5 & $(3,5,7)$ & $1 / 5$ & $(1 / 7,1 / 5,1 / 3)$ \\
6 & $(4,6,8)$ & $1 / 6$ & $(1 / 8,1 / 6,1 / 4)$ \\
7 & $(5,7,9)$ & $1 / 7$ & $(1 / 9,1 / 7,1 / 5)$ \\
8 & $(6,8,10)$ & $1 / 8$ & $(1 / 10,1 / 8,1 / 6)$ \\
9 & $(7,9,11)$ & $1 / 9$ & $(1 / 11,1 / 9,1 / 7)$ \\
\hline
\end{tabular}

where $\mathrm{i}=1,2,3 \ldots \ldots \mathrm{r}, \mathrm{j}=1,2,3 \ldots \ldots \mathrm{s}$ and $\mathrm{k}=\mathrm{r}$, or $\mathrm{k}=\mathrm{s}$. After that, a fuzzy weighted performance matrix (W) can thus be obtained by multiplying the weight vector with the decision matrix.

$$
\tilde{\mathrm{W}}=\tilde{\mathrm{A}}_{\mathrm{i}} * \tilde{\omega}_{\mathrm{j}}=\left(\begin{array}{c}
\left(\mathrm{w}_{1 l} \mathrm{a}_{11 l} \mathrm{w}_{1 \mathrm{~m}} \mathrm{a}_{11 \mathrm{~m}} \mathrm{w}_{1 \mathrm{u}} \mathrm{a}_{11 \mathrm{u}}\right) \\
\left(\mathrm{w}_{2 l} \mathrm{a}_{21 l} \mathrm{w}_{2 \mathrm{~m}} \mathrm{a}_{21 \mathrm{~m}} \mathrm{w}_{2 \mathrm{u}} \mathrm{a}_{21 \mathrm{u}}\right) \\
\cdot \\
\cdot \\
\cdot \\
\left(\mathrm{w}_{\mathrm{nm}} \mathrm{a}_{\mathrm{ijl}} \mathrm{w}_{\mathrm{nm}} \mathrm{a}_{\mathrm{ijm}} \mathrm{w}_{\mathrm{nm}} \mathrm{a}_{\mathrm{iju}}\right)
\end{array}\right) ;
$$

$$
=\left(\begin{array}{c}
\mathrm{W}_{11} \mathrm{~W}_{1 \mathrm{~m}} \mathrm{~W}_{1 \mathrm{u}} \\
\mathrm{W}_{21} \mathrm{~W}_{2 \mathrm{~m}} \mathrm{~W}_{2 \mathrm{u}} \\
\cdot \\
\cdot \\
\cdot \\
\mathrm{W}_{\mathrm{il}} \mathrm{W}_{\mathrm{im}} \mathrm{W}_{\mathrm{iu}}
\end{array}\right)
$$

Step 3: Fuzzy number ranking evaluation: In order to make a crisp choice among the alternatives, we need to check and compare the ranking of the fuzzy numbers. We apply the alpha-cuts-based method $1^{[14]}$ to the total weighted performance matrices for each alternative and check the ranking consistency for each alternative under different alpha level. The alpha-cuts-based method 1 states that if let $\tilde{\mathrm{A}}$ and $\tilde{\mathrm{B}}$ be fuzzy numbers with $\alpha$-cuts, $\mathrm{A}_{\alpha}=\left[\mathrm{a}_{\alpha}{ }^{-}, \mathrm{a}_{\alpha}{ }^{+}\right]$and $\mathrm{B}_{\alpha}=\left[\mathrm{b}_{\alpha}{ }^{-}, \mathrm{b}_{\alpha}{ }^{+}\right]$. It say $\mathrm{A}$ is smaller than $\mathrm{B}$, denotes by $\tilde{\mathrm{A}} \leq \tilde{\mathrm{B}}$, if $\mathrm{a}_{\alpha}{ }^{-}<\mathrm{b}_{\alpha}{ }^{-}$and $\mathrm{a}_{\alpha}{ }^{+}$ $<\mathrm{b}_{\alpha}{ }^{+}$for all $\alpha \in(0.1]$. The advantage of this method is the conclusion is less controversial.

Step 4: Confidence level fuzzy number: A level threshold $(0, \alpha, 1)$ of the fuzzy set is defines to show the decision-makers' confidence to their judgements. The confidence value ranges between 0 and 1 , from the least confidence to the most confidence. The definition of the symmetrical triangle fuzzy number $(\mathrm{f}=(1, \mathrm{~m}, \mathrm{u}))$ with the interval confidence at level, $\alpha$, can be determined by: 


$$
\begin{aligned}
& \tilde{\mathrm{W}}_{a}=\left(\begin{array}{c}
{\left[\mathrm{W}_{\text {lleft }}^{\alpha}, \mathrm{W}_{\text {llight }}^{\alpha}\right]} \\
{\left[\mathrm{W}_{2 \text { left }}^{\alpha}, \mathrm{W}_{\text {2right }}^{a}\right]} \\
\cdot \\
\cdot \\
\cdot \\
{\left[\mathrm{W}_{\text {ilett }}^{a}, \mathrm{~W}_{\text {iright }}^{\alpha}\right]}
\end{array}\right) \text {, where } \\
& \mathrm{W}_{\text {Left }}^{\alpha}(\mathrm{i})=[\alpha(\mathrm{m}-\mathrm{l})+1] \quad \text { and } W_{\text {Right }}^{\alpha}(i)=[\alpha(m-u)+u] \\
& \text { respectively. }
\end{aligned}
$$

Step 5: Optimistic level evaluations: The nature optimistic level of the decision maker can be optimistic, moderate or pessimistic. The decision maker's optimistic level with fixed $\alpha$ is denotes as:

$$
\mathrm{DM}_{\lambda}^{\alpha}(\mathrm{i})=\lambda \mathrm{W}_{\text {right }}^{\alpha}(\mathrm{i})+(1-\lambda) \mathrm{W}_{\text {left }}^{\alpha}(\mathrm{i})
$$

where $\lambda \in[0,1]$. This crisp performance matrix is represents by:

$$
C_{\lambda}^{\alpha}=\left(\begin{array}{c}
D M_{\lambda}^{\alpha}(1) \\
D M_{\lambda}^{\alpha}(2) \\
\cdot \\
\cdot \\
\cdot \\
D M_{\lambda}^{\alpha}(i)
\end{array}\right)
$$

Finally, we normalize the $C_{\lambda}^{\alpha}(i)$ to evaluate the highest degree of suitability among the selection with respect to i-alternatives using the following formula:

$$
\mathrm{C}_{\lambda}^{\alpha}(\mathrm{i})=\frac{\mathrm{C}_{\lambda}^{\alpha}(\mathrm{i})}{\sum \mathrm{C}_{\lambda}^{\alpha}(\mathrm{i})}
$$

\section{EMPIRICAL APPLICATION}

Problem formulation: Consider a fresh graduate student would like to choose a job that can provide overall satisfactions in term of benefits, colleagues, location and reputation. Says, the available jobs are job $\mathrm{A}, \mathrm{B}$ and $\mathrm{C}$. The problem formulation process involves the goal, criteria and alternatives (three level hierarchy) as indicates in Fig. 1. When the user has a clear picture in mind regarding the problem, one can start by inserting the values for each level in the main page. Else, the system provides a domain information repository (DIR) and Google search to assist the user in problem determination.

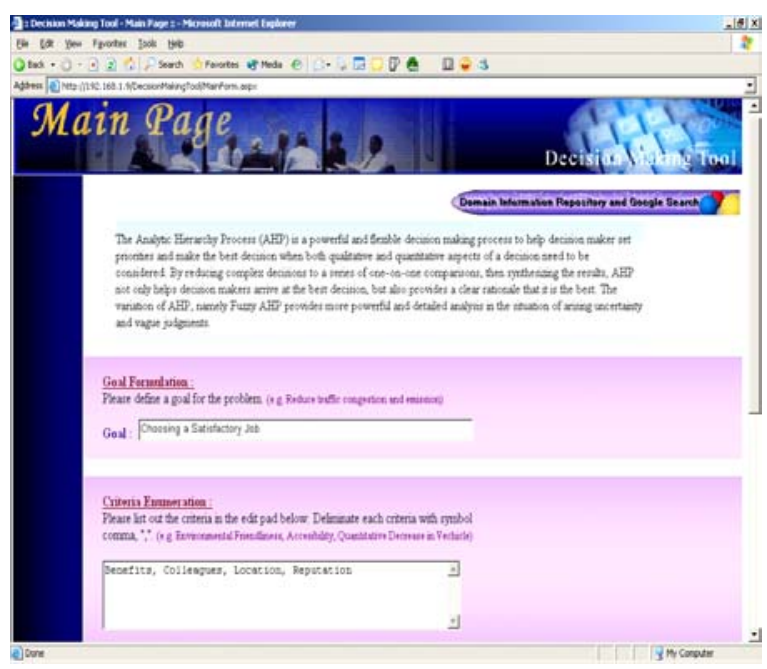

Fig. 1: Main page

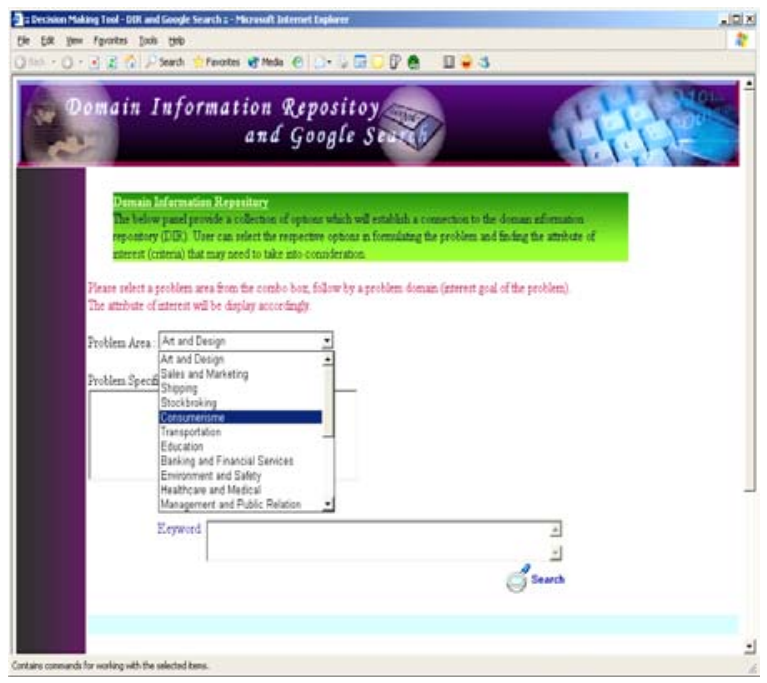

Fig. 2: Domain information repository (DIR) and Google search

Pairwise comparison: After the problem formulation (goal, criteria and alternatives), the system moves to the state of accepting pairwise judgment from the user. The scoring scale is according to the Saaty's original scale $^{[1,2]}$.

Consistency checking: Before viewing the result of the AHP operation, user can select PCM Consistency Check (Fig. 3) button to check whether the evaluations are consistent (Fig. 4) enough to be useful. If the evaluation is inconsistent, the system will alert the user to redefine the pairwise comparison for the PCM. 


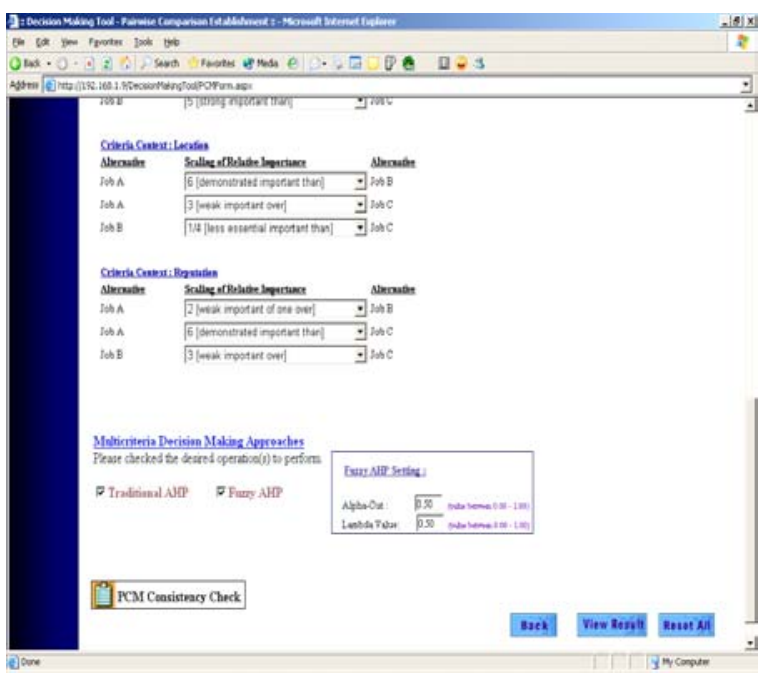

Fig. 5: Fuzzy Ranking Check

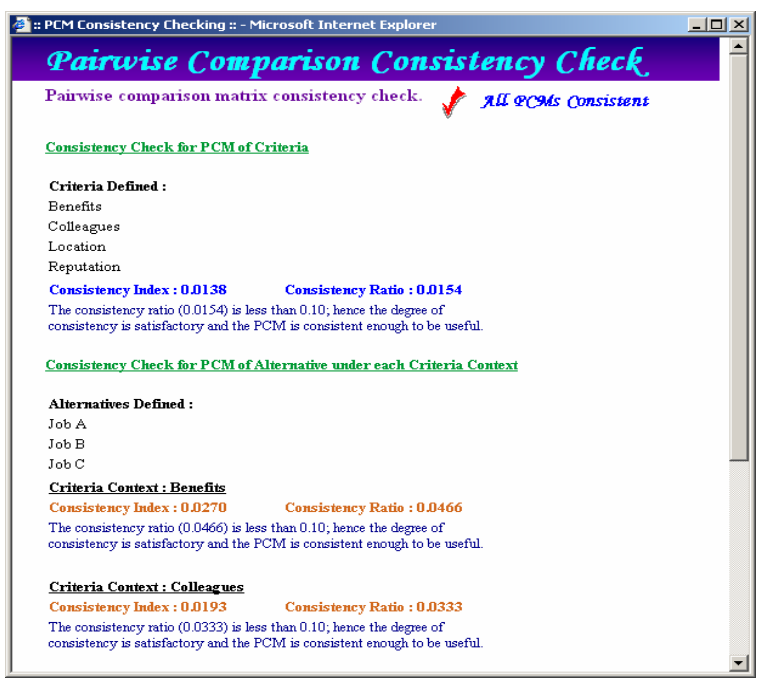

Fig. 6: Synthesis Result for Fuzzy AHP

In order to make a crisp choice among the alternatives, alpha-cuts-based method is uses to check and compare the fuzzy number at all alpha level at certain point of optimistic threshold.

Result visualization: Finally, the results are indicated in Fig. 6.

\section{CONCLUSION}

This program achieves simplicity and abstraction with fuzzy AHP algorithm that works behind the scene. The Web bases feature enhances the accessibility and portability of this tool. In addition, we also integrate the domain information repository to assist the user with the information (criteria and alternatives) for certain common problem domains.

\section{REFERENCES}

1. Saaty, T.L., 1980. The Analytic Hierarchy Process. New York, McGraw Hill.

2. Saaty, T.L., 1994. Fundamentals of Decision making and priority theory with the Analytic Hierarchy Process. RWS Publications: Pittsburgh.

3. Ghodsypour, S.H. and C. O'Brien, 1998. A decision support system for supplier selection using an integrated analytic hierarchy process and linear programming. Int. J. Prod. Econ., 56: $199-212$.

4. Badri, M.A., 2000. Combining the AHP and goal programming for global facility location-allocation problem. Int. J. Prod. Econ., 62: 237-248.

5. Tsoi, R.H.L., 2001. Using analytic hierarchy process method to prioritise human resources in substitution problem. Int. J. Comput. Internet Manage., 9: 25-36.

6. Chin, K.S., S. Chiu and V.M.R. Tummala, 1999. An evaluation of success factors using the AHP to implement ISO 14001- based ESM. Int. J. Qual. Reliability Manage., 16: 341-361.

7. Udo, G.G., 2000. Using analytic hierarchy process to analyze the information technology outsourcing decision. Ind. Manage. Data Syst., 100: 421-429.

8. Cheng, C.H., 1996. Evaluating naval tactical missile systems by fuzzy AHP based on the grade value of membership function. Eur. J. Operat. Res., 96: 343-350.

9. Mon, D.L., 1995. Evaluating Weapon System Using Fuzzy Analytic Hierarchy Process Based on Entropy Weight. Proceedings of IEEE International Fuzzy Systems and The Second International Fuzzy Engineering Symposium, 2: 591-598.

10. Kahraman, C., U. Cebeci and D. Ruan, 2004. Multi-attribute comparison of catering service companies using fuzzy AHP: The case of Turkey. Int. J. Prod. Econ., 87: 171-184.

11. Kuo, R.J., C.C. Chi and S.S. Kao, 2002. A decision support system for selecting convenience store location through integration of fuzzy AHP and artificial neural network. Computers Industry, 47: 199-214.

12. Tam, M.C.Y. and V.M.R. Tummala, 2001. An application of the AHP in vendor selection of a telecommunication system. Omega, 29: 171-182.

13. Chin, W.C., K.W.H. Yeow and K.L. Ng, 2000. Web server future planning decision analysis-fuzzy linguistic weighted approach. Fourth International Conferennce on Knowledge-Based Intelligent Engineering Systems and Allied Technologies, Brighton UK., pp: 826-830.

14. Wang, L.X., 1997. Course in Fuzzy Systems and Control, Prentice Hall Inc. 